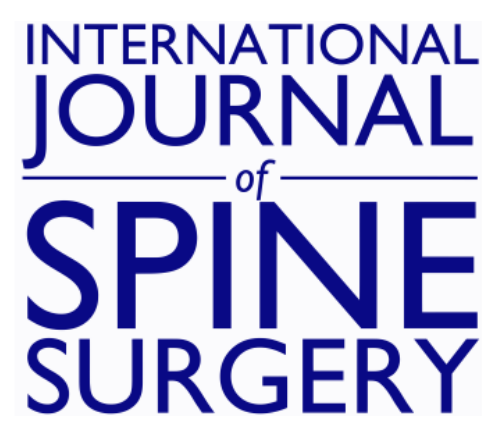

\title{
A Comparison of the Degree of Lateral Recess and Foraminal Enlargement With Facet Preservation in the Treatment of Lumbar Stenosis With Standard Surgical Tools Versus a Novel Powered Filing Instrument: A Cadaver Study
}

Murat Cosar, Larry T. Khoo, Christopher A. Yeung and Anthony T. Yeung

Int J Spine Surg 2007, 1 (4) 135-142

doi: https://doi.org/10.1016/SASJ-2007-0107-NT-R1

http://ijssurgery.com/content/1/4/135

This information is current as of April 26, 2023.

Email Alerts Receive free email-alerts when new articles cite this article. Sign up at:

http://ijssurgery.com/alerts

The International Journal of Spine Surgery

2397 Waterbury Circle, Suite 1,

Aurora, IL 60504, Phone: +1-630-375-1432 


\title{
A Comparison of the Degree of Lateral Recess and Foraminal Enlargement With Facet Preservation in the Treatment of Lumbar Stenosis With Standard Surgical Tools Versus a Novel Powered Filing Instrument: A Cadaver Study
}

Murat Cosar, MD, Larry T. Khoo, MD, Christopher A. Yeung, MD, and Anthony T. Yeung, MD

ABSTRACT

Background

The SurgiFile (SurgiFile, Inc., Carlsbad, California) is a specialized tool designed for the treatment of lateral recess and foraminal stenosis that allows surgeons to internally expand and decompress the entire length of the neural foramen while preserving the integrity of the overlying facet complex.

\section{Methods}

We used two cadaveric specimens in this study. After they removed the lamina and spinous processes of L2, L3, L4, and L5 from the dorsal spine, fellowship-trained spinal surgeons used the standard tools and the SurgiFile to the best of their experience and ability on alternating sides of each level to decompress the lateral recess and neural foramen while still preserving at least $50 \%$ of the dorsal facet complex. Using preoperative and postoperative fine-cut CT scans with axial and sagittal reconstructions, we evaluated the degree of decompression and the amount of preserved facet complex using analytical tests and recording the measurements.

\section{Results}

The difference between the proximal recess and lateral foramen of the groups was statistically significant in the axial CT images. On sagittal reconstruction CT images, the difference between the two groups was significant $(P<0.05$, Wilcoxon) only for the lateral foramen. Although a strong trend toward better area change was evident for the proximal recess measurements in the experimental tool sides, this did not achieve statistical significance. Macroscopic and CT scans measurements showed that the amount of facetectomy for adequate decompression with the SurgiFile was less than the amount achieved with the standard tools.

\begin{abstract}
Conclusions
For the treatment of spinal stenosis, this novel powered-file instrument provides surgeons with a new means of decompressing the lateral recess and neural foramina. In this cadaveric study, procedures performed with the SurgiFile tool showed a statistically superior degree of decompression as compared with the standard surgical instruments and techniques.
\end{abstract}

Key Words Foraminal stenosis, lateral recess, spinal stenosis, spinal surgery. SAS Journal. Autumn 2007; 1:135-142. DOI: SASJ-2007-0107-NT-R1

\section{INTRODUCTION}

The central spinal canal and foramen are defined by both bony structures (vertebral body, facets, pedicles) and soft tissue structures (ligamentum flavum, facet capsules, intervertebral disc annulus). With the aging process, degenerative changes occur in the spine, causing narrowing of the central spinal canal area, the proximal foramen (eg, lateral recess) and the lateral aspect of the spinal foramina. With progressive aging, by the dehydration of nucleus pulposus, the area between individual vertebrae decreases. A decrease in the disc height can often lead to impingement of the vertebral endplates and facet joints, resulting in spondylosis and the formation of reactive osteophytes. ${ }^{1-3}$ Consequently, the formation of marginal endplate osteophytes, subsidence and subluxation of the facet processes, secondary loss of foraminal height, and thickening of the ligamentum flavum are the major degenerative changes that lead to narrowing of the central canal and neural foramen (Table 1).

Classically, laminectomy, laminotomy, and foraminotomy have been used in varying combinations to treat spinal stenosis. ${ }^{1,4-7}$ The degree of decompression, especially for the proximal recess and neural foramen, are limited by the degree of facet resection. Whereas most decompressions do not lead 
Table 1

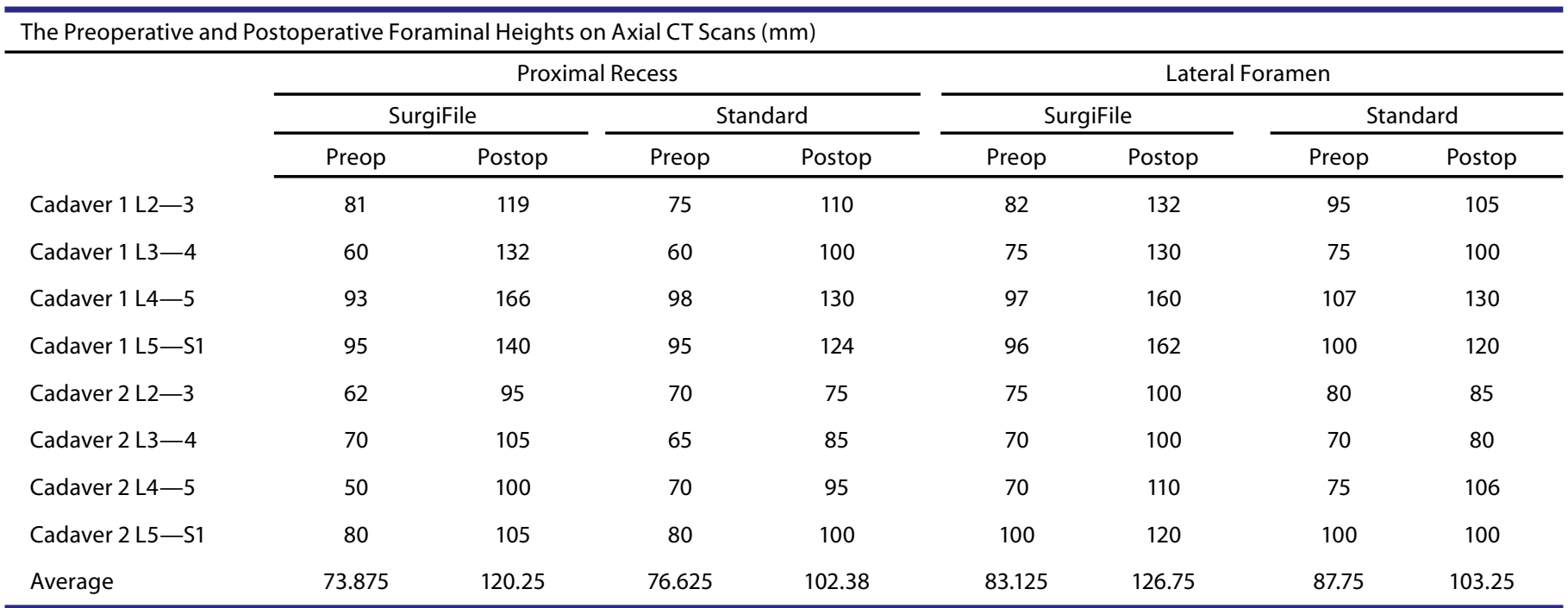

to postoperative spinal instability, over $30 \%$ to $50 \%$ of these procedures can result in early or delayed spondylolisthesis. ${ }^{8,9}$ For such cases, spinal fusion may also be required to support the primary decompressive procedures., ${ }^{4-18}$ As a result of this balance between the degree of decompression and the amount of induced postoperative spinal instability, incomplete decompression of the exiting nerves remains one of the most common causes of failed back syndrome in the literature. ${ }^{13,19,20}$

We present our initial evaluation of a new surgical tool, the SurgiFile (SurgiFile, Inc., Carlsbad, California), which employs a thin powered-file blade designed to slip into the proximal recess and then internally expand the neural foramen along its entire course by shaving off encroaching osteophytes and impinging facet edges while maximally preserving the overlying facet joint complex. We compared the effectiveness of this tool in achieving neural decompression with that of standard surgical techniques in a cadaveric lumbar experimental study.

\section{Technical Properties of the SurgiFile Tool}

The SurgiFile is a novel surgical tool for decompression of the neural foramen while sparing the overlying facet joint complex as much as possible and protecting the underlying neural elements (Figure 1). Its patented toroidal drive functionally converts a standard rotating motor drive's cylindrical spinning motion (ie, Stryker TPS, Anspach eMax, Midas Rex Legend) into a smooth oscillating linear motion that is used to directly drive a specially created file blade. This is accomplished without using cams or gears, thereby delivering a driving force to the cutting blade with minimum torque, heat, and energy loss. Once an adequate surgical exposure of the spinal lamina has been made via small laminotomy or laminectomy, the thin oscillating blade of the device is then used to expand the neural foramen from inside out, a technique that is in direct contrast with the standard approach of outside-in decompression for treatment of spinal stenosis (Figure 2).

\section{Figure 1}

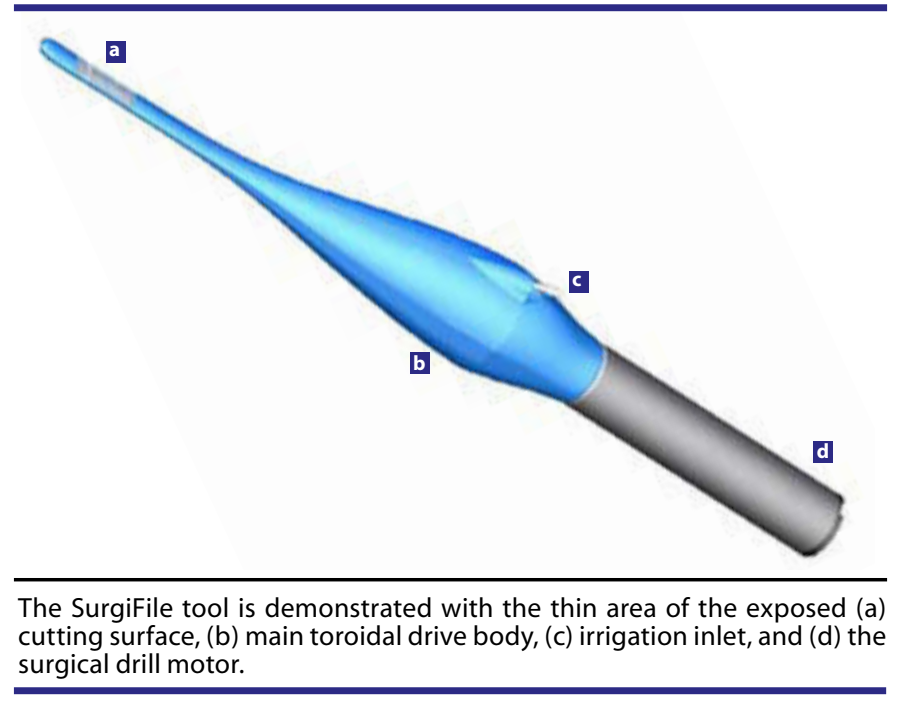

The surface of the cutting blade contains small raised "cuttingcones" that effectively shave hard cortical bone into small micron-sized particles that are washed away by the flow of saline solution provided by the integrated irrigation pump and delivered through a small portal within the shaft of the blade. With the use of standard suction tips, the surgeon is able to advance the tool progressively through the length of the neural corridor with a minimum of stoppages or exchanges because the particles are too small to clog the suction tips.

Finally, the SurgiFile can be rotated around the dorsal aspects of the foramen, thus allowing the surgeon to decompress not only the osteophytes on the "roof" of the corridor but also those along the "side" walls of the foramen. The SurgiFile maintains the integrity of the stabilizing facet complex during foraminal decompression because it works using an inside-out technique and does not require resection of the overlying joint to gain access to the medial and lateral foraminal areas (Table 2). This 
Figure 2

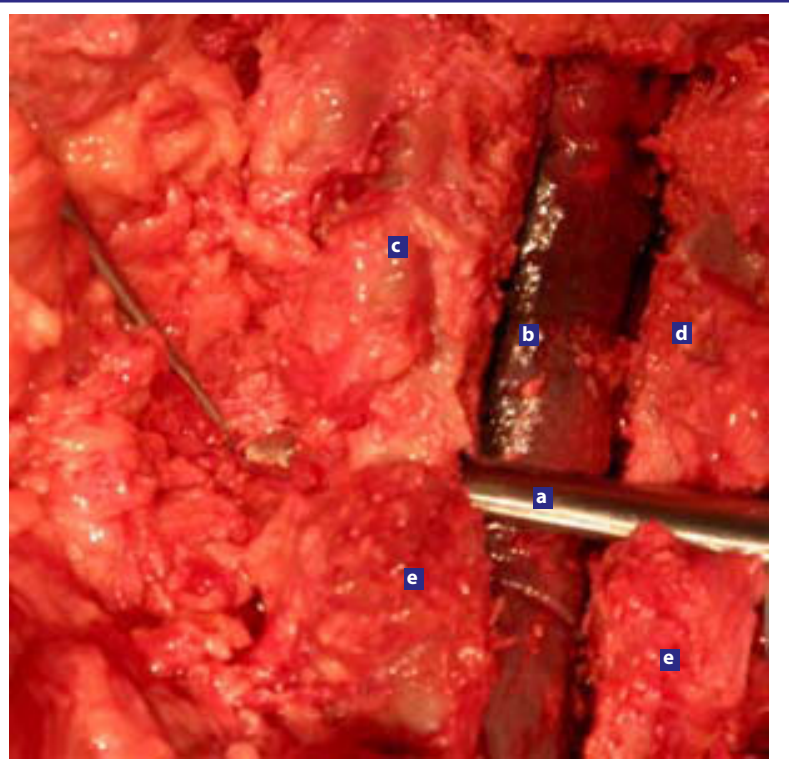

(a) The Surgifile tool is demonstrated here completing an inside-to-outside decompression along the entire length of the neural foraminal corridor. Because only the dorsal surface of the working blade is active, the SurgiFile tip can be used directly over the exposed (b) thecal sac and nerve root. (c) SurgiFile side. (d) Standard side. (e) Facet joint.

capability is in stark contrast to standard techniques, which require resection of the overlying facet complex with either a drill or Kerrison rongeurs to provide access to the underlying neural foramen. Even with aggressive undercutting, such standard surgical techniques often result in significant resection of the facet complex, thereby contributing to the phenomenon of postoperative spinal instability, which can be avoided with the use of the SurgiFile for decompression.

\section{MATERIALS AND METHODS}

In two cadaveric lumbar segments, preoperative axial and sagittal CT scans (5 mm overlapping, noncontrast sequences, bone windows) were obtained to visualize and document the size of the lateral recess and neural foramen at the L2-3, L3-4, L4-5, and L5-S1 levels. The cadavers were checked to ensure that there was no deformity or severe osteoporosis or prior spinal surgical decompression that could confound the experimental results. The medial-lateral height of the neural foramen and recess were measured on axial CT bone window slices. The level of the proximal recess was defined as the area immediately adjacent to the medial border of the superior articulating facet process and the medial border of the pedicle. The level of the lateral foramen was defined as the area immediately subadjacent to the lateral aspect of the inferior articulating facet process and lateral border of the pedicle (Figure 3). On sagittal reconstructions, cross-sectional area measurements were obtained at the level of the proximal recess and lateral foramen as well. These measurements were calculated with the aid of standard computer-based visualization and image analysis software at the L2-3, L3-4, L4-5, and L5-S1 levels.

Three experienced fellowship trained neurological and orthopedic spinal surgeons performed the experimental decompressions. During the operative portion of the procedure, the surgeons used a standard midline approach with subperiosteal exposure of the L2-S1 lamina and subsequent placement of self-retaining retractors. The dissection was carried out more laterally than for usual laminectomy procedures to provide full exposure of the facet complex. The spinous processes were then resected with a midline laminectomy performed to the level of the medial facet using standard Kerrison rongeurs and an airpowered surgical drill with a matchstick bit attachment.

Once the midline decompression was achieved, the surgeons performed lateral recess and foraminal decompression in a rotating fashion using either standard surgical tools (surgical drill with matchstick attachment/Kerrison rongeurs/curettes) or the SurgiFile blade (with only initial use of curettes and Kerrisons to enter the proximal recess). The extent of the decompression

Table 2

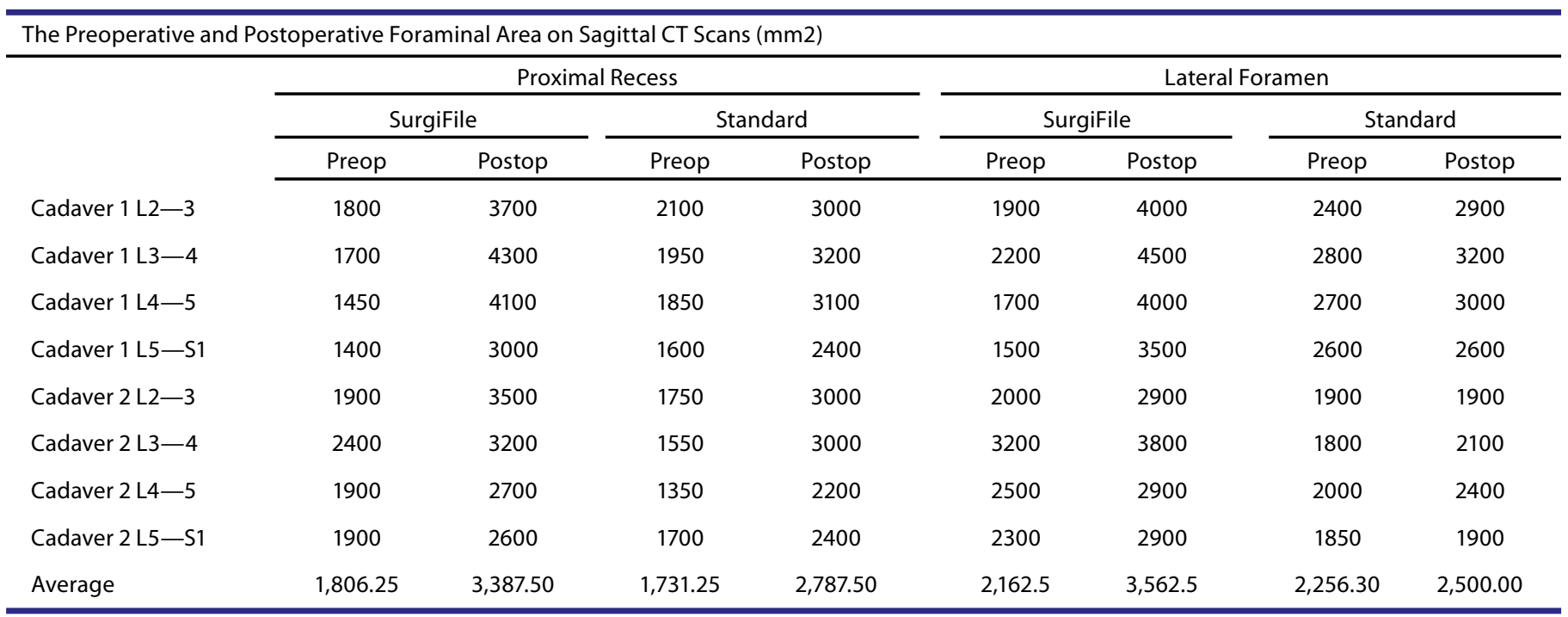


Figure 3

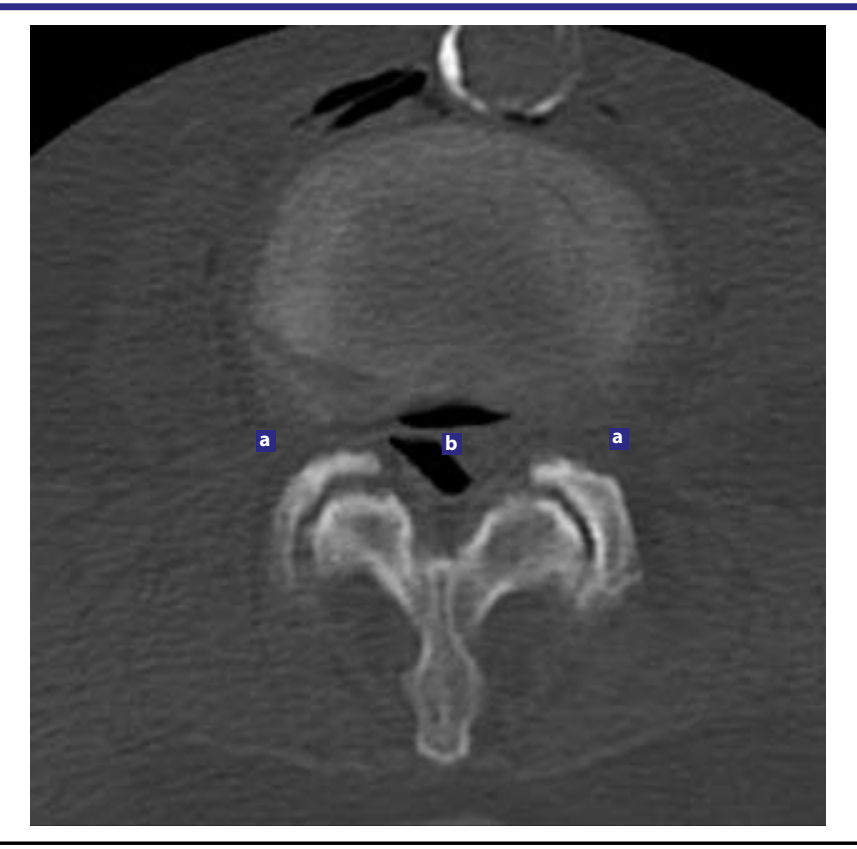

The landmarks of the neural foramen are shown in the axial CT scan image. (a) Lateral foramen; (b) proximal recess.

was stopped when the operative surgeon observed that no more facet could be safely resected to maintain segmental stability (more than 50\%) or that the proximal recess and neural foramen had been completely decompressed, as confirmed by Woodson elevators and nerve hooks. The decompressions were carried out on a side-to-side comparison between the control and experimental groups. The SurgiFile tool was used in the leftsided lumbar foramina in the first cadaver (four levels: L2-3, L3-4, L4-5, and L5-S1) and the right-sided lumbar foramina in the second cadaver. In each spinal level Woodson elevators were used intraoperatively for quantitative assessment of the decompression (poor/good). The surgeons determined the extent of facet resection achieved (less than $25 \%, 25 \%$ to $50 \%$, $50 \%$ to $75 \%$, or more than $75 \%$ ). After the decompression procedure, the two cadavers were re-imaged by CT fine-cut scanning using the same protocol as we used preoperatively. The blinded-radiologist was also determined and recorded these measurements.

\section{RESULTS}

The foraminal length and area in the medial and lateral parts of the lumbar vertebral foramina were measured before and after laminectomy, and the foraminal decompression was assessed using axial and sagittal CT scans in conjunction with computerized image viewing and analysis software (Tables 3 and 4; Figure 4a, 4b). Comparing the raw preoperative and postoperative data, we observed a clear absolute numerical increase in the foraminal height on axial imaging and in the cross-sectional area on sagittal imaging in both the standard and SurgiFile groups. After the sizes of recess and lateral foramina were measured on axial and sagittal CT scans, the
Table 3

\begin{tabular}{|c|c|c|c|c|}
\hline \multicolumn{5}{|c|}{ Preop and Postop Foraminal Length Increase on Axial CT Scans (\%) } \\
\hline & \multicolumn{2}{|c|}{ Proximal Recess } & \multicolumn{2}{|c|}{ Lateral Foramen } \\
\hline & SurgiFile & Standard & SurgiFile & Standard \\
\hline Cadaver $1 \mathrm{~L} 2-3$ & 1800 & 3700 & 2100 & 3000 \\
\hline Cadaver $1 \mathrm{~L} 3-4$ & 1700 & 4300 & 1950 & 3200 \\
\hline Cadaver 1 L4-5 & 1450 & 4100 & 1850 & 3100 \\
\hline Cadaver $1 \mathrm{~L} 5-\mathrm{S} 1$ & 1400 & 3000 & 1600 & 2400 \\
\hline Cadaver $2 \mathrm{~L} 2-3$ & 1900 & 3500 & 1750 & 3000 \\
\hline Cadaver 2 L3-4 & 2400 & 3200 & 1550 & 3000 \\
\hline Cadaver 2 L4-5 & 1900 & 2700 & 1350 & 2200 \\
\hline Cadaver 2 L5-S1 & 1900 & 2600 & 1700 & 2400 \\
\hline Average & $1,806.25$ & $3,387.50$ & $1,731.25$ & $2,787.50$ \\
\hline
\end{tabular}

Table 4

\begin{tabular}{|c|c|c|c|c|}
\hline \multicolumn{5}{|c|}{ Preop and Postop Foraminal Area Increase on Sagittal CT Scans (\%) } \\
\hline & \multicolumn{2}{|c|}{ Proximal Recess } & \multicolumn{2}{|c|}{ Lateral Foramen } \\
\hline & SurgiFile & Standard & SurgiFile & Standard \\
\hline Cadaver $1 \mathrm{~L} 2-3$ & 105 & 42 & 110 & 20 \\
\hline Cadaver $1 \mathrm{~L} 3-4$ & 150 & 45 & 104 & 15 \\
\hline Cadaver 1 L4-5 & 182 & 65 & 135 & 11 \\
\hline Cadaver $1 \mathrm{~L} 5-\mathrm{S} 1$ & 114 & 50 & 133 & 0 \\
\hline Cadaver $2 \mathrm{~L} 2-3$ & 84 & 71 & 45 & 0 \\
\hline Cadaver 2 L3-4 & 34 & 100 & 20 & 16 \\
\hline Cadaver 2 L4-5 & 42 & 62 & 16 & 20 \\
\hline Cadaver 2 L5-S1 & 37 & 41 & 26 & 2 \\
\hline Average & 93,5 & 59,5 & 73,625 & 10,5 \\
\hline
\end{tabular}

percentage of change in the height and cross-sectional area for the proximal recess and lateral foramen was calculated for the standard and SurgiFile groups, respectively (Figure 5a, 5b, 5c, 5d). As predicted, an absolute increase was seen in terms of percent change for both groups as well (Figure 6a, 6b).

The results of the statistical analysis revealed that the percentage of change in the proximal recess and lateral foraminal height on axial CT scans was significantly higher in the SurgiFile group $(P<0.05$, Wilcoxon). Similarly, the percentage of change in the lateral foraminal cross-sectional sagittal areas was significantly higher in the SurgiFile group $(P<0.05$, Wilcoxon). Although we observed a clear and strong trend toward larger absolute cross-sectional areas in the postoperative group at the level of the proximal recess, these differences did not achieve statistical significance $(P=0.263$, Wilcoxon).

On axial and sagittal CT images, the facet complex and intervening joint line could be seen. 


\section{Figure 4}

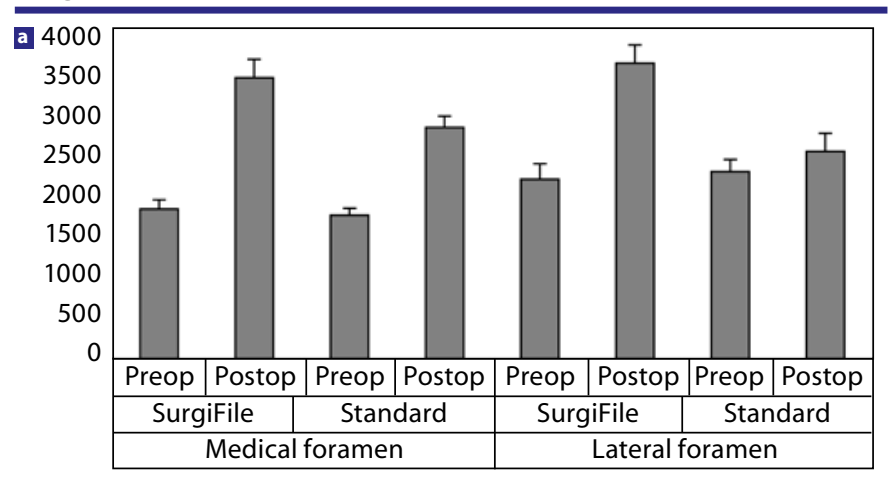

b

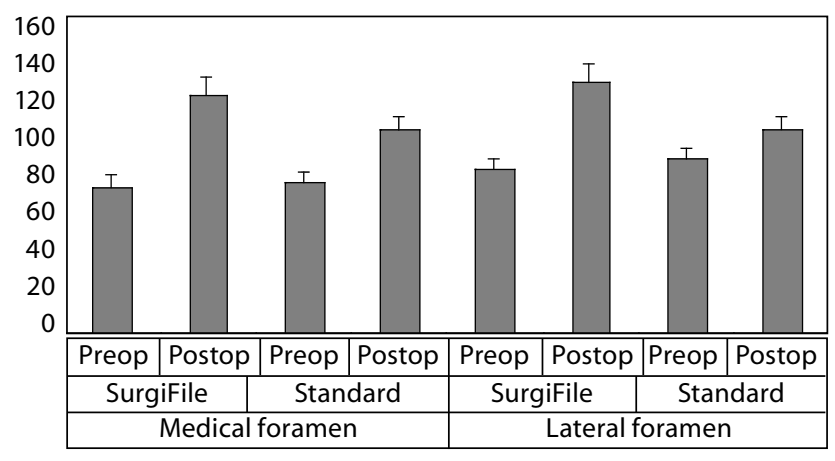

(a) Axial A-P foraminal sizes; and (b) sagittal foraminal areas are shown.

However, the facet volumes could not be measured with absolute certainty due to the constraints of the imaging technique and the analysis software. Qualitatively, however, more of the facet complex was maintained at nearly every level in the SurgiFile group, as seen on CT imaging and direct visual inspection (Figure 7a, 7b).

\section{DISCUSSION}

In this cadaver study, we compared the standard tools (drill, Kerisson ronguers, and others) with a novel tool-SurgiFilethat was specifically designed for the treament of recess and foraminal stenosis with the aim of maximal decompression while maintaining the integrity of the overlying facet complex. The beginning of the surgical procedures (removal of spinous process, laminectomy) was similar in both the experimental and control groups. After the laminectomy step, the surgeons used the SurgiFile for foraminal decompression on one side of the lumbar segment and the standard tools (drill, Kerrison, curettes) on the other side. The blindly evaluated results suggest that the SurgiFile tool maintains the stability of the vertebrae with qualitatively greater preservation of the overlying facet complex while decompressing the neural elements.

Central canal stenosis is far less common than the syndromes of lateral recess and foraminal stenosis from facet hypertrophy in combination with encroachment of the intervertebral discs. Decompression of the traversing and exiting roots is a common goal in operative treatment for spinal stenosis. Because the facet joint forms the dorsal border of both the proximal and lateral neural foramen,
Figure 5

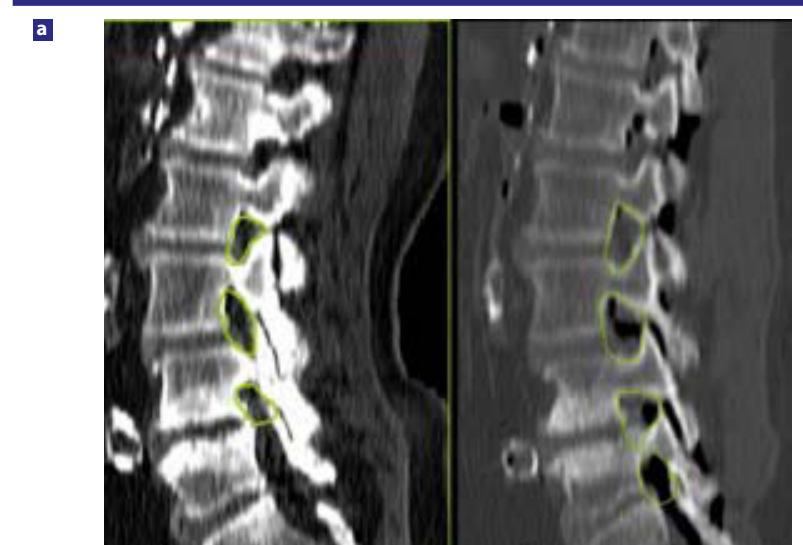

b

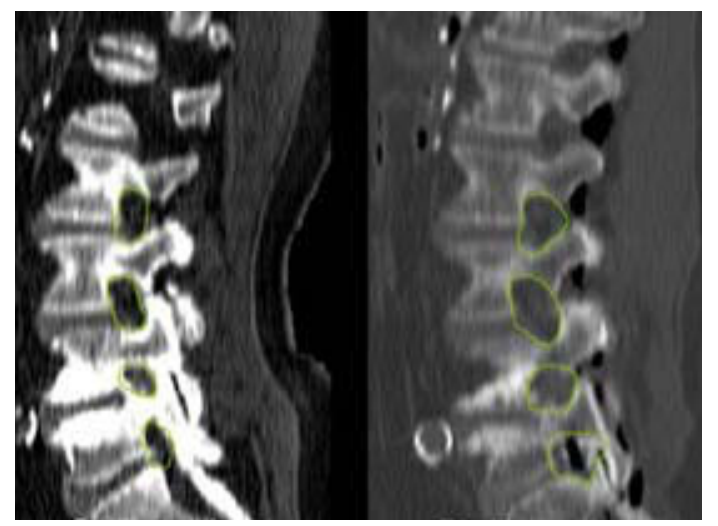

c

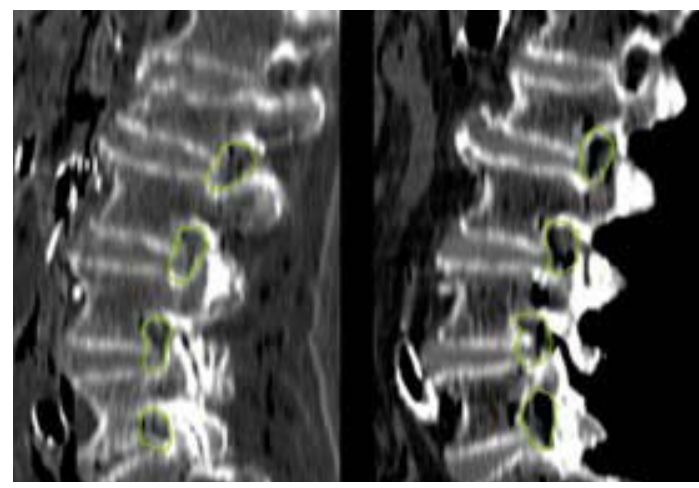

d

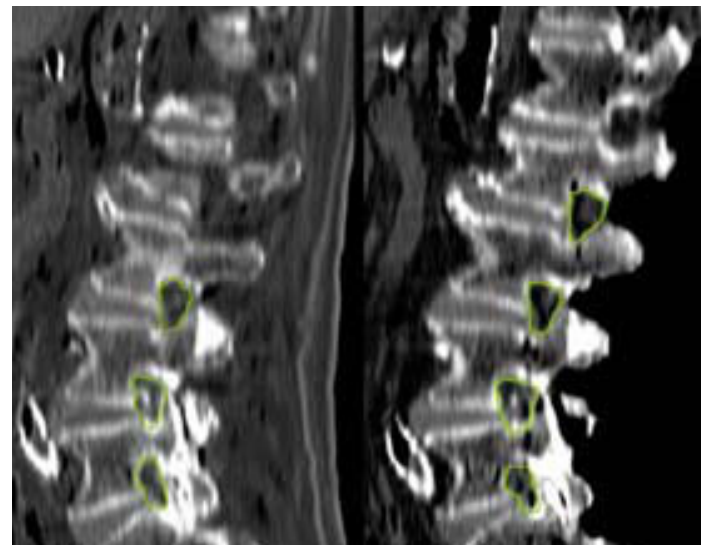

Comparison of sagittal CT scans showing (a) medial proximal recess areas before (left) and after (right) use of Surgifile tool; (b) lateral foraminal areas before (left) and after (right) use of SurgiFile tool; (c) medial foraminal areas before (left) and after (right) use of standard tools; and (d) lateral foraminal areas before (left) and after (right) use of standard tools. 


\section{Figure 6}

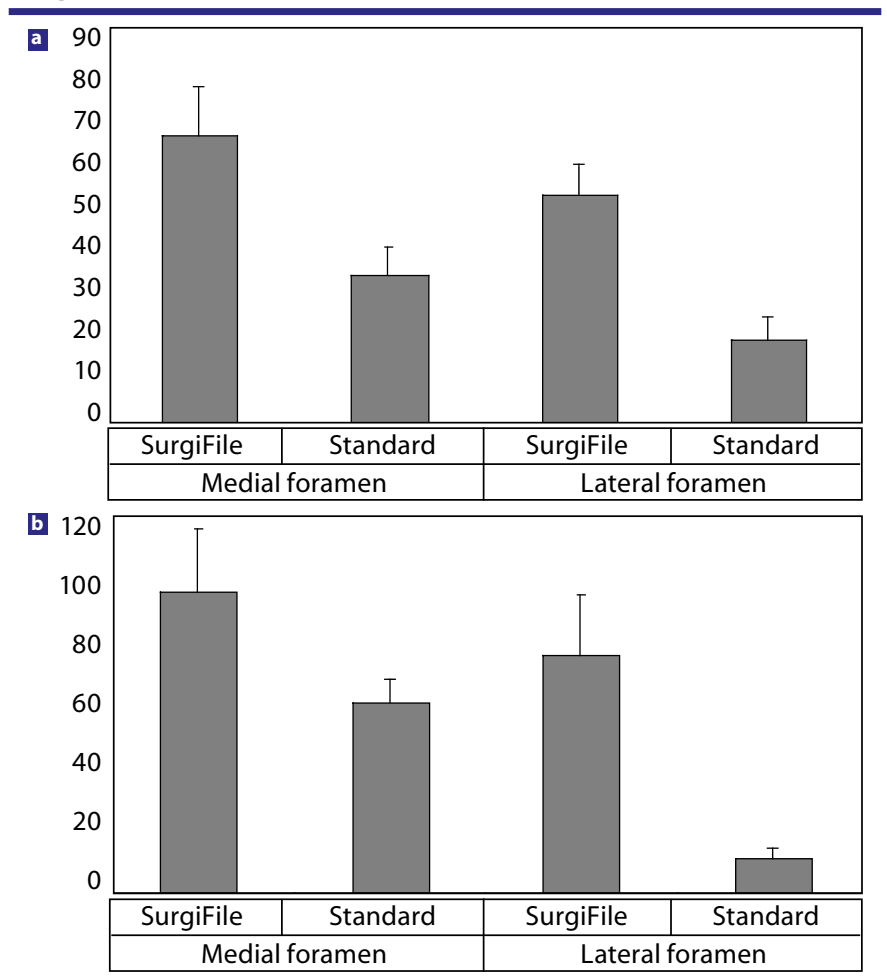

(a) Postoperative change in Axial A-P foraminal distance; and (b) percentage of change in the sagittal foraminal area.

successful nerve decompression typically mandates some bony resection of the joint complex. This effect is classically achieved with a combination of drilling and undercutting with Kerisson ronguers in an angled fashion..$^{5,8,19,20}$ Due to the outside-in approach used in traditional spinal surgery, a certain degree of facet joint violation and destabilization is inevitable during most operations for spinal stenosis. Consequently, during classical decompression of the affected neural elements in spinal stenosis using standard surgical tools, iatrogenic destabilization of the operated spinal segments can occur early or be progressive over time. The balance between these two opposing goals results in the commonly encountered clinical problems of either persistent radiculopathy when the neural elements are not adequately decompressed or spinal instability and back pain when the foramen is fully decompressed and too much of the facet joint complex has been resected. ${ }^{5-7,13,17}$

We think that the SurgiFile tool may allow surgeons to perform an internal decompression not only of the adjacent lamina at the level of the surgical procedure but also of the entire neural foramen. After initially creating enough laminotomy exposure with standard currettes and Kerrisons, the surgeons could maneuver the SurgiFile angled tip in the same manner as with a Woodson to engage the internal surface of the laminofacet junction undersurface. Then, through the oscillating action of the SurgiFile, the surgeon can rapidly and safely file down the inner cortex of the lamina to widen the spinal
Figure 7

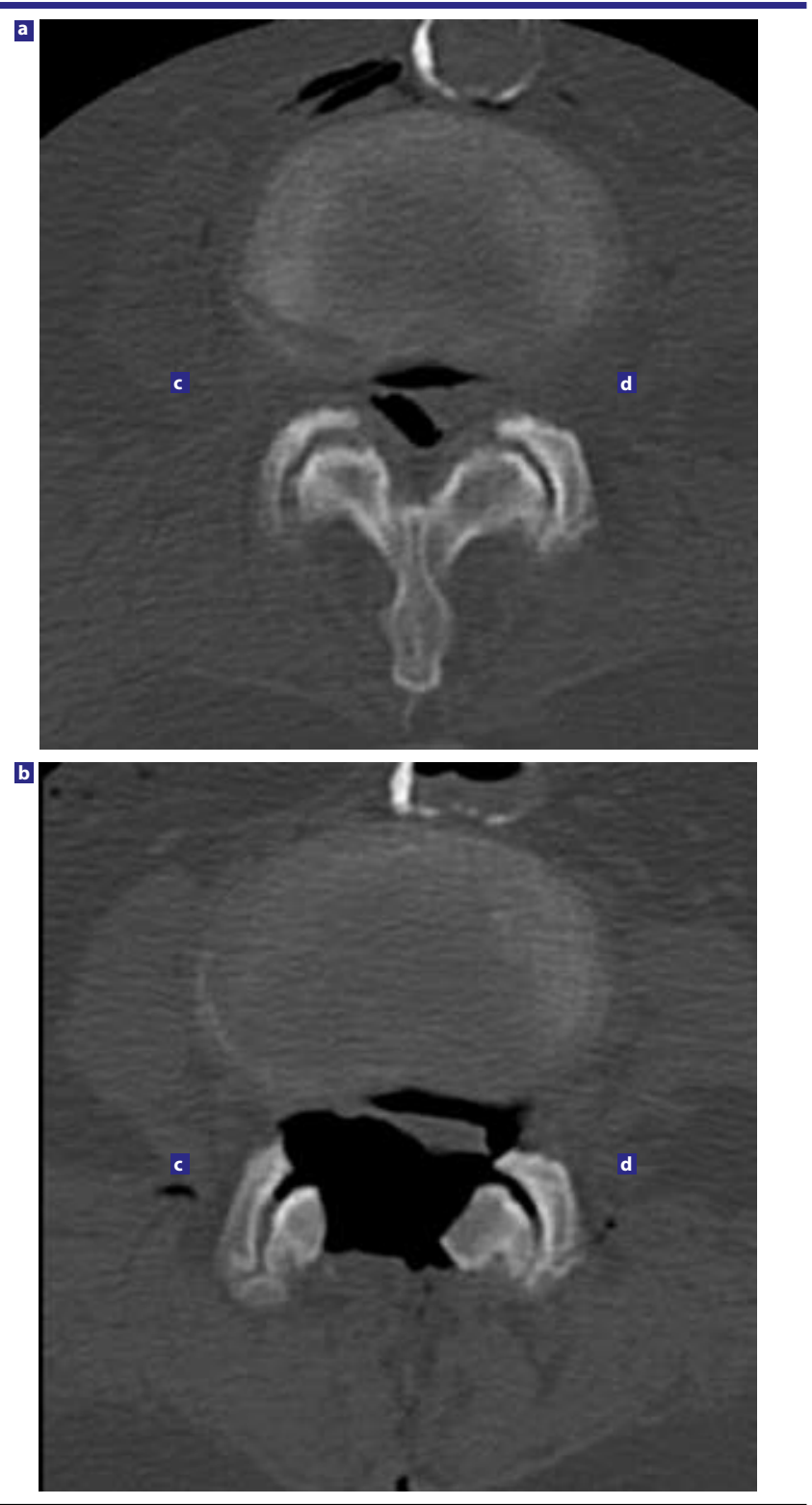

(a) Preoperative macroscopic visual comparison of the SurgiFile versus the standard sides demonstrates the greater facet preservation overall in the Surgifile side after neural decompression; (b) Postoperative comparisons of the; (c) Standard side on axial CT demonstrates greater qualitative preservation of the facet joints; and the (d) SurgiFile side.

canal. The SurgiFile is thus shielded to protect the underlying neural structures. The SurgiFile tip could be steered rostrally and caudally to undercut further the adjacent lamina while preserving the outer cortex of the lamina with its functionally important musculo-ligamentous attachments. The surgeon enters the lateral recess or proximal aspect of the neural foramen with the tip of the SurgiFile tool. The tool is then used to achieve an internal decompression from the inside out of the neural foramen while maximally preserving the articulating surface of the facet joint complex. Because the tool can be rotated around the cylinder of the nerve root, the impinging facets can be decompressed both rostrally and caudally along 
the side walls of the neural foramen. Because the inferior surface of the SurgiFile tip is smooth, it could be passed safely along the surface of the existing nerve root all the way to the lateral foramen to achieve a complete decompression along the entire length of the foraminal cylinder. Both of these operative maneuvers are unique to the SurgiFile tool. Finally, the risk of inadvertent dural injury during decompression appears to be less for the SurgiFile blade with its protected undersurface as compared to the biting edge of the Kerrison rongeurs or the more perilous tip of the spinning drill bit.

We think that the potential for neural injury with the SurgiFile blade is less than that for standard tools because of the smooth undersurface area and oval-shaped edges. A small amount of risk might result from the heat generated by the device during oscillation, but this can be eliminated by washing the operation area with saline through the irrigation inlet of the device. This model of the SurgiFile device is suitable for some cases of minimally invasive surgery, but if the angle of the blade is increased, it could be used in most minimally invasive surgery cases.

In this cadaver study, we performed facetectomy at all levels and demonstrated an increase in the size of the proximal recess and lateral foramina overall in both the SurgiFile and standardtool groups after foraminotomy. However, the average increases in the actual height $(\mathrm{mm})$ and cross-sectional areas $\left(\mathrm{mm}^{2}\right)$ at both the proximal recess and lateral foramina were greater in the SurgiFile group than in the control group. Analysis of the differences in percent change for proximal recess and lateral foraminal height on axial CT scans also revealed statistically significant differences between the SurgiFile and standard groups ( $P<0.05$, Wilcoxon). As decompression of the proximal foramen or lateral recess can be readily achieved via both existing standard surgical tools and the SurgiFile blade, the percent change between two groups for proximal recess areas was not significant $(P=0.263$, Wilcoxon). Whereas decompression with standard tools had to be stopped more medially to avoid excessive resection of the facet, the SurgiFile cutting blade was easily rotated and passed along the nerve out to the lateral border of the foramen. Consequently, the middle and outer sections of the neural foramen were far less effectively decompressed in the standard group. As a result, the percent change in the lateral foraminal cross-sectional areas was statistically greater with the SurgiFile than with the standard tools $(P<0.05$, Wilcoxon).

Because the SurgiFile worked from the inside-out as opposed to the outside-in technique of undercutting with Kerrison rongeurs and drill bits, we were able to observe a far greater degree of facet preservation in the SurgiFile group on gross visual inspection and on CT axial scan images (Figure 7a, 7b). Based on examples from the clinical and biomechanical literature, greater preservation of the functional facet joint would likely decrease the risk of iatrogenic postlaminectomy instability and thereby avoid the need for simultaneous or subsequent spinal fusion..$^{8,9}$
With the increasing popularity of less invasive spinal surgical techniques, the SurgiFile blade will also allow surgeons to decompress spinal stenosis through a minimally invasive laminotomy exposure. Because the blade can shave off spurs and the internal aspects of the facet and lamina, the outer cortices of the bony spinal anatomy, with its functionally important muscular and ligamentous attachments, remain intact. This technique may offer the additional benefits of decreased muscle trauma and blood loss, more rapid postoperative recovery, and better long-term function for older patients with lumbar stenosis. In cases of lumbar total disc replacement, preexisting disease and previous surgical resection of the facet are relative contraindications. The minimally invasive inside-out type of decompression achievable with the SurgiFile blade may be particularly relevant in the emerging age of spinal arthroplasty, for which the primary objective is to maintain the overall motion and dynamic stability of the spinal segment.

Based on these findings and our initial experience with the SurgiFile blade, we believe that it offers several potential clinical advantages over the existing standard surgical tools used for spinal decompression. These advantages include more effective recess and foraminal decompression, better facet preservation, decreased incidence of postoperative or iatrogenic instability, and less need for subsequent arthrodesis and stabilization. Ultimately, the SurgiFile blade may fundamentally alter the manner in which surgeons treat spinal stenosis, thereby reducing the risk, morbidity, and complication rates of these procedures.

Murat Cosar, MD, Larry T. Khoo, MD, Christopher A. Yeung, MD, and Anthony T. Yeung, MD

From the Department of Neurosurgery, Canakkale 18 Mart University of Medical School, Canakkale, Turkey (Cosar), the Division of Neurosurgery, UCLA, Los Angeles, California (Khoo), and the Arizona Institute for Minimally Invasive Spine Care, Phoenix, Arizona (C.A. Yeung and A.T. Yeung).

Address correspondence and reprint requests to Murat Cosar, MD, Canakkale 18 Mart University, Faculty of Medicine, Department of Neurosurgery, 17200 Canakkale, Turkey (email:drcosar@hotmail.com).

This submission was received July 3, 2007 and accepted on October 18, 2007.

Note: There are no outside funding sources for authors of this study.

This study was approved by the Institutional Review Board.

\section{REFERENCES}

1. Herno A, Saari T, Suomalainen O. The degree of decompressive relief and its relation to clinical outcome in patients undergoing surgery for lumbar spinal stenosis. Spine. 1999;24:1010-1014.

2. Johnsson KE, Rosen I, Uden A. The natural course of lumbar spinal stenosis. Clin Orthop. 1992;279:82-86.

3. Katz JN, Dalgas M, Stucki G, Lipson SJ. Diagnosis of lumbar spinal stenosis. Rheum Dis North Am. 1994;20:471-483. 
4. Atlas SJ, Keller RB, Wu YA, Deyo RA, Singer DE. Long-term outcomes of surgical and nonsurgical management of lumbar spinal stenosis: 8 to 10 year results from the main lumbar spine study. Spine. 2005;30(8):936-943.

5. Guigui P, Barre E, Benoist M, and Deburge A. Radiologic and computed tomography image evaluation of bone regrowth after wide surgical decompression for lumbar stenosis. Spine. 1999;24:281-289.

6. Guiot BH, Khoo LT, Fessler RG. A minimally invasive technique for decompression of lumbar spine. Spine. 2002;27:432-438.

7. Ikuta K, Arima J, Tanaka T, Oga M, Nakano S, Sasaki K, et al. Shortterm results of microendoscopic posterior decompression for lumbar spinal stenosis. Technical note. J Neurosurg Spine. 2005;2(5):624-633.

8. Johnsson KE, RedlundJohnell I, Eden ALF, Willner S. Preoperative and postoperative instability in lumbar spinal stenosis. Spine. 1989;14:591-593.

9. Katz JN, Stucki G, Lipson SJ, et al. Predictors of surgical outcome in degenerative lumbar spinal stenosis. Spine. 1999;21:2229-2233.

10. Airaksinen O, Herno A, Turunen V., Surgical outcome of 438 patients treated surgically for lumbar spinal stenosis. Spine. 1997;22:2278-2282.

11. Aryanpur J, Ducker T. Multilevel lumbar laminotomies: An alternative to laminectomy in the treatment of lumbar stenosis. Neurosurgery. 1990;26:429-433.

12. Khoo LT, Fessler RG. Microendoscopic decompressive laminotomy for the treatment of lumbar stenosis. Neurosurgery. 2002;51(Suppl 2):144-151.

13. Lin PM. Internal decompression for multiple levels of lumbar spinal stenosis: a technical note. Neurosurgery. 1982;11(4):546- 549.

14. Matsudaira K, Yamazaki T, Seichi A, Takeshita K, Hoshi K, Kishimoto J. Spinal stenosis in grade I degenerative lumbar spondylolisthesis: a comparative study of outcomes following laminoplasty and laminectomy with instrumented spinal fusion. J Orthop Sci. 2005;10(3):270- 276.

15. Postacchini F. Spine Update: Surgical management of lumbar spinal stenosis. Spine. 1999;24:1043-1047.

16. Sanderson PL, Wood PLR. Surgery for lumbar spinal stenosis in old people. J Bone Joint Surg [Br]. 1993;75:393-397.

17. Tsai RYC, Yang RS, Bray RS. Microscopic laminotomies for degenerative lumbar spinal stenosis. J Spin Dis. 1998;11:389-394.

18. Tuite GF, Stern JD, Doran SE, et al. Outcome after laminectomy for lumbar spinal stenosis, part I: Clinical correlations. J Neurosurg. 1994;81:699-706.

19. Herron LD, Mangelsdorf C. Lumbar stenosis: results of surgical treatment. J Spinal Disord. 1991;4:26-33.

20. Hurri H, Slatis P, Soini K. Lumbar spinal stenosis: Assessment of longterm outcome 12 years after operative and conservative management. $J$ Spin Dis. 1998;11:110- 115. 